\title{
REDUCTION OF POST-SURGICAL PERICARDIAL ADHESIONS USING A PIG MODEL
}

Thesis submitted by

Ali Alizzi, MB.Ch.B, M.D

in

January 2005

in fulfillment of the requirements for the research degree of

Master of Medicine

in the School of Veterinary and Biomedical Sciences

and School of Medicine

James Cook University 


\section{ELECTRONIC COPY}

I, the undersigned, the author of this work, declare that the electronic copy of this thesis provided to the James Cook University Library, is an accurate copy of the print thesis submitted, within the limits of the technology available.

Signature

Date 


\section{DECLARATION}

I declare that this thesis is my own work and has not been submitted in any form for another degree or diploma at any university or other institute of tertiary education. Information derived from the published or unpublished work of others has been acknowledged in the text and a list of references is given.

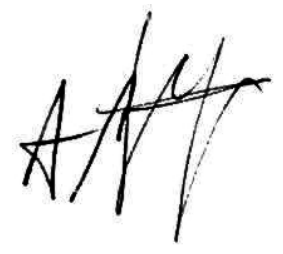

A Alizzi

January 2005 


\section{STATEMENT OF ACCESS TO THESIS}

I, the undersigned, the author of this thesis, understand that James Cook University will make it available for use within the university library and, by microfilm or other photographic means, allow access to users in other approved libraries. All users consulting this thesis will have to sign the following statement:

In consulting this thesis I agree not to copy or closely paraphrase it in whole or in part without the written consent of the author, and to make proper written acknowledgment for any assistance which I have obtained from it.

Beyond this, I do not wish to place any restriction on access to this thesis.

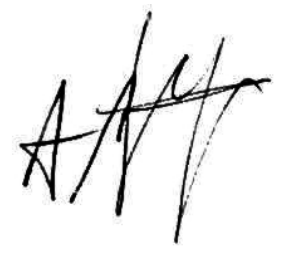

A Alizzi

January 2005 


\section{ACKNOWLEDGMENTS}

I would like to sincerely thank Professor Phillip Summers for his kind guidance, supervision and provision of facilities and operating funds for this project. I also thank Drs. Ben Bidstrup and Mo Diqer for their contribution and advice throughout the study period. My sincere appreciation goes to Ms.Virginia Boon, School of Pharmacy and Molecular Sciences for her major contribution in establishing the assays and measuring plasma concentrations of indomethacin, rofecoxib, prostaglandin E2 and thromboxane.

I appreciate the kind assistance of Mr. Chris Coleman and Mr. Scott Blyth, Animal Technicians from the School of Veterinary and Biomedical Sciences at James Cook University. Both were responsible for the husbandry of the animals and provided assistance in preparing the animals for surgery and collection of blood. I sincerely thank Dr. Belinda Leslie and Dr. John Potter of the Townsville Veterinary Clinic who provided anaesthesia for the pigs throughout the study.

My appreciation also goes to Dr. David Williams, chief anatomical pathologist at The Townsville Hospital for his histopathological examination of cardiac tissue.

I would also like to thank Ms. Susan Wright and Mr. Paul Jacob, clinical photographers, The Townsville Hospital for their efforts in the preparation and editing of the images throughout the project. My thanks are extended to Dr. Mike Steele of James Cook University-Cairns who gave advice on the statistical analysis of the results.

I also acknowledge the kind assistance of the following companies and institutions for their support during this study:

- The Private Research Trust Fund, The Townsville Hospital for providing me with a two year scholarship and funding for the project.

- The staff at the School of Veterinary and Biomedical Sciences, James Cook University, Townsville.

- $\quad$ The Townsville Vet Clinic. 
- Tag Medical Australia, specifically Mrs. Marie Pearce for supplying the CoSeal throughout the study period.

- Johnson \& Johnson, specifically Ms.Cathy Shelly, for their kind donation of all the suture material used. 


\begin{abstract}
The aim of this study was to reduce pericardial adhesions after open-heart surgery thus enabling re-sternotomies to be much safer and less time consuming for the surgical team. A pig model was developed to test the effects of non-steroidal antiinflammatory drugs (NSAIDs) and a barrier method in reducing post-surgical pericardial adhesions. Four groups (11 per group) of pigs 8-12 weeks of age were used. Group one was the control group, Group two received indomethacin, Group three received rofecoxib (also a NSAID) and a polyethyleneglycol (Co-Seal) was applied to the pericardium as a barrier in Group four.
\end{abstract}

After performing a median sternotomy, an adhesion induction model was applied to maximize inflammation in the pericardium. This included abrasion of the heart surface, leaving blood in the pericardium and drying of tissues. The chest was then closed. In Group four, Co-Seal was sprayed on the heart before closure. Postoperatively, Groups two and three received indomethacin and rofecoxib respectively for five days. Plasma markers of inflammation were assessed on days 2, 5 and 10 post-operative. In each group, eight animals were re-opened after 12 weeks and three after 25 weeks to assess adhesions according to adhesion assessment scales. Tissue samples were collected for histopathological examination looking mainly at epicardial and adhesive tissue thickness.

It was observed in this study that adhesions were changed from dense to thin and more easily separable, requiring more blunt rather than sharp dissection. This was seen mainly in Group two, followed by Group four. In Group three, the changes were less in terms of amount of adhesions and tenacity change as compared to the changes in Groups two and four. Comparison was with Group one, which had the densest adhesions.

Adhesive tissue and epicardial thickness was measured. Epicardium was thinnest in Group two. Post-operative inflammatory markers, specifically PGE2 and TXB2 were inhibited mainly in Group two. Less inhibition of these markers was seen in Group three and nearly no inhibition was seen in Groups one and four. The more general 
markers used (WCC, ESR and CRP) did not fully show the expected changes in the four groups. The adhesion induction model formulated in this study was successful and may be used in similar future projects.

In conclusion, this model, applied clinically, will reduce adhesions in the pericardium and retrosternal areas after surgery, rendering re-openings safer and less time consuming. Indomethacin has proven to be the best choice to achieve this following a relatively easy and short protocol of administration. The idea of giving patients indomethacin for five days only to achieve significant reduction in adhesion formation after surgery would be attractive to many surgical groups around the world as the short period of administration would minimize any side effects associated with this drug.

Significant reduction in adhesions was also seen following the application of CoSeal. The attraction here would be the ease of use and the non-pharmacological effects of this barrier method. Rofecoxib was not as effective as indomethacin and Co-seal in adhesion reduction. Future studies in this pig model should examine the extent of adhesion formation following the combined use of indomethacin and CoSeal. 


\section{TABLE OF CONTENTS}

Page

Declaration

Statement of Access to Thesis

ii

Acknowledgements

Abstract

Table of Contents

List of Tables

List of Figures

Abbreviations

1.1 Cardiac surgery and pericardial adhesions

1.2 Complications of post-operative adhesion formation

1.3 Adhesion formation

1.4 Reduction of adhesion formation

1.5 The pig model

1.6 Hypothesis and aim of the study

iv

vi

viii

$\mathrm{xi}$

xiv

Chapter2 Literature Review

2.1 Surgical aspects of adhesions 5

2.2 Incidence of adhesions

$\begin{array}{ll}2.3 \text { Adhesive problems in cardiac surgery } & 7\end{array}$

2.4 Economic burden of adhesions $\quad 8$

2.5 Mesothelial repair 9

2.6 Mechanisms of adhesion formation $\quad 10$

$\begin{array}{ll}2.6 .1 \text { Causative factors } & 10\end{array}$

$\begin{array}{ll}2.6 .2 \text { Adhesion formation } & 10\end{array}$

$\begin{array}{ll}2.7 \text { Assessment of adhesion } & 12\end{array}$

2.8 Adhesion re-formation $\quad 14$

2.9 Role of inflammation in adhesion formation 15

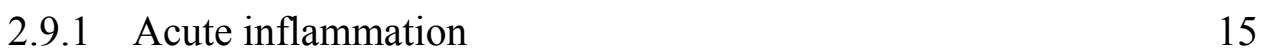

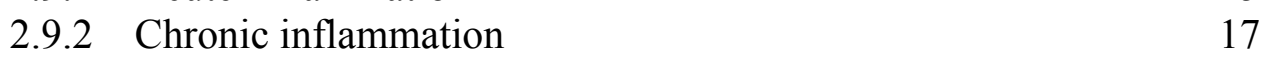

$\begin{array}{ll}2.9 .3 \text { Biochemical events } & 18\end{array}$

2.9.3.1 Chemical inflammatory mediators $\quad 18$

2.9.3.2 Chemotaxis and leukocyte activation 21

2.9.3.3 Arachidonic acid (AA) metabolites - Prostaglandins and Leukotrienes (Eicosanoids 23

2.10 Non-Steroidal Anti-Inflammatory Drugs (NSAIDs) 27

2.10.1 History 27

2.10.2 Mechanism of action of NSAIDs 28

2.10.3 Cyclooxygenase-1 and Cyclooxygenase-2 30

2.10.4 Side effects of NSAIDs 32 
2.11 The Pig as a laboratory model for human disease 34

2.11.1 Introduction 34

2.11.2 Comparative anatomy and physiology of the pig 34

2.11.2.1 Cardiovascular System $\quad 35$

2.11.2.2 Digestive System 36

$\begin{array}{lll}\text { 2.11.2.3 Urogenital system } & 37\end{array}$

2.11.2.4 Integumentary and Lymphatic Systems 38

2.12 Summary of literature review $\quad 39$

\section{$\begin{array}{lll}\text { Chapter } 3 \text { Material and Methods } & 41\end{array}$}

3.1 Animals 41

3.2 Establishment of drug dosages 41

$\begin{array}{lll}3.3 & \text { Surgical trial } & 42\end{array}$

3.3.1 Anaesthesia $\quad 42$

3.3.2 Surgical Procedure 43

$\begin{array}{ll}\text { 3.3.3 Post-operative care } & 47\end{array}$

$\begin{array}{ll}3.4 \text { Additional Groups } & 48\end{array}$

3.5 Inflammatory markers in peripheral blood 48

3.6 Re-openings 49

3.7 Statistical Analysis $\quad 51$

Chapter 4 Gross and Microscopic Evaluation of Post-Operative Pericardial Adhesions $\quad 52$

4.1 Introduction $\quad 52$

4.2 Results 52

4.2.1 Effect of the surgical procedures on the animals 52

4.2.2 Adverse effects of indomethacin treatment 53

4.2.3 Housing period 54

4.2.4 Results of re-sternotomy 55

4.2.5 Gross evaluation of adhesions 55

4.2.6 Effects of omeprazole on adhesion formation 57

4.2.7 Microscopic evaluation of adhesions $\quad 59$

$\begin{array}{lll}4.3 \text { Discussion } & 60\end{array}$

4.3.1 Adhesion Induction Model 60

4.3.2 Gross adhesion evaluation 61

4.3.3 Microscopic evaluation $\quad 62$

4.3.4 Effect of indomethacin on the gastrointestinal tract $\quad 62$

4.3.5 Effect of omeprazole on adhesion formation 63

4.3.6 Application of Co-Seal 63

$\begin{array}{lll}4.4 & \text { Summary } & 64\end{array}$

Chapter 5 Plasma concentrations of anti-inflammatory drugs and inflammatory markers

5.1 Introduction $\quad 65$

5.2 Results 66

5.2.1 Non steroidal anti-inflammatory plasma levels and inflammatory inhibition 
5.2.1.1 Indomethacin 66

5.2.1.2 Rofecoxib 67

5.2.2 Coagulation screen 67

5.2.2.1 Activated Partial Thromboplastin Time $\quad 68$

5.2.2.2 Prothrombin Time 69

5.2.2.3 International Normalization Ratio 69

5.2.3 Inflammatory markers results before and after surgery in all groups $\quad 70$

$\begin{array}{lll}\text { 5.2.3.1 White cell counts } & 70\end{array}$

5.2.3.2 Erythrocyte sedimentation rate $\quad 71$

5.2.3.3 C- reactive protein concentrations $\quad 73$

5.2.3.4 Prostaglandin E2 concentrations $\quad 75$

5.2.3.5 Thromboxane B2 concentrations 76

$\begin{array}{lll}5.3 \text { Discussion } & 77\end{array}$

5.4 Summary 81

$\begin{array}{llr}\text { Chapter } 6 & \text { General Discussion } & 82\end{array}$

6.1 The pig model 83

6.2 Selection of drug doses $\quad 84$

6.3 Surgical procedures, induction and assessment of cardiac Adhesions 85

6.4 Inflammatory markers in peripheral blood 87

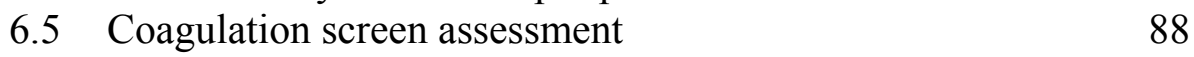

6.6 Future research directions $\quad 89$

$\begin{array}{ll}6.7 \text { Conclusion } & 90\end{array}$

$\begin{array}{lr}\text { References } & 91\end{array}$ 


\section{LIST OF TABLES}

Page

Table 2.1 Grading system for pericardial adhesions (Seegar et al. 1997) .......... 13

Table 2.2 Scoring system for adhesive bands............................... 13

Table 2.3 Inflammatory actions of eicosanoids............................. 26

Table 3.1 Relation between animal weight and endotracheal tube size.......... 43

Table 4.1 Averages for the Adhesion Percentage Scale (APS) and Adhesive Tissue Tenacity Scale (ATTS) for each group re-opened after 12 weeks..................................................... 56

Table 4.2 Averages for the Adhesion Percentage Scale (APS) and Adhesive Tissue Tenacity Scale (ATTS) for each group re-opened after 25 weeks 56

Table 4.3 Probability values of the comparison of the average value for APS and ATTS of each of the treatment groups with the control group in all animals.

Table 4.4 Averages for the Adhesion Percentage Scale (APS) and Adhesive Tissue Tenacity Scale (ATTS) for the additional groups treated with omeprazole.

Table 4.5 Average thickness in millimeters of epicardium in all groups according to time of re-opening.

Table 4.6 Average thickness in millimeters of retrosternal adhesions in all groups according to time of re-opening.

Table 4.7 Probability values of the comparison of the thickness in millimeters of epicardium of each of the treatment groups with the control group in all animals according to time of re-opening.

Table 4.8 Probability values of the comparison of the thickness in millimeters of retrosternal adhesions of each of the treatment groups with the control group in all animals according to time of re-opening.

Table 5.1 Relationship between indomethacin plasma concentration and plasma concentration of prostaglandin E2 and thromboxane $\mathrm{B} 2$ in pig 1 
Table 5.2 Relationship between rofecoxib plasma concentration and plasma concentration of prostaglandin E2 and thromboxane B2 in pig 2

Table 5.3 Average values for the activated partial thromboplastin time in all animal groups before surgery (baseline) and after surgery (days 2, 5, and 10).

Table 5.4 Average values for the prothrombin time in all animal groups before surgery (baseline) and after surgery (days 2, 5, and 10)

Table 5.5 Average values for the international normalization ratio in all animal groups before surgery (baseline) and after surgery (days 2, 5, and 10).

Table 5.6 Probability values for the activated partial, thromboplastin time change after surgery between all groups.

Table 5.7 Probability values for the prothrombin time change after surgery between all groups. .70

Table 5.8 Probability values for the international normalization ratio change after surgery between all groups 70

Table 5.9 Mean $\left( \pm\right.$ SEM) white cell counts x $10^{9} / \mathrm{L}$ for the four groups of pigs... 71

Table 5.10 Mean $( \pm$ SEM) erythrocyte sedimentation rate $(\mathrm{mm} / \mathrm{hr})$ values for the four groups of pigs. .73

Table 5.11 Mean ( \pm SEM) C-reactive protein $(\mathrm{mg} / \mathrm{L})$ concentrations for the four groups of pigs

Table 5.12 Mean ( \pm SEM) prostaglandin E2 $(\mathrm{pg} / \mathrm{ml})$ values for the four groups of pigs

Table 5.13 Mean ( \pm SEM) thromboxane B2 $(\mathrm{pg} / \mathrm{ml})$ concentrations for the four groups of pigs 78 


\section{LIST OF FIGURES}

Page

Figure 2.1 Dilated blood vessel during acute inflammation (taken from www.med.und.nodak.edu/depts/path/pathlab/inflammation). .15

Figure 2.2 Chemical mediators of inflammation (adapted from Cotran et al. 1994).19

Figure 2.3 Scanning electron microscopy of a moving leukocyte showing the pseudopod (taken from Cotran et al. 1994)

Figure 2.4 Generation of arachidonic acid metabolites and their roles in inflammation (taken from Cotran et al. 1994). .25

Figure 3.1 Heart exposed after opening the pericardium. .44

Figure 3.2 The placement of aortic and atrial sutures. 46

Figure 4.1 Group 1 (control) showing extensive adhesions on re-opening the sternum.

Figure 4.2 Group 2 (indomethacin) with thin adhesions and a coronary artery clearly visible 58

Figure 4.3 Group 4 (Co-Seal) with the heart easily dissected off the pericardium...58

Figure 4.4 Group 3 (rofecoxib) with more adhesions as the heart was dissected....58

Figure 5.1 Mean total white cell count in each group before and after surgery $(\mathrm{N}=4$ per group $)$

Figure 5.2 Mean erythrocyte sedimentation rate before and after surgery in each group $(\mathrm{N}=4$ per group $)$.

Figure 5.3 Mean C-reactive protein concentration before and after surgery in each group $(\mathrm{N}=4$ per group).

Figure 5.4 Mean prostaglandin E2 concentrations before and after surgery in each group $(\mathrm{N}=4$ per group).

Figure 5.5 Mean thromboxane B2 concentrations before and after surgery in each group $(\mathrm{N}=4$ per group) 


\section{ABBREVIATIONS}

\begin{tabular}{|c|c|}
\hline AA & Arachidonic acid \\
\hline AMP & Adenosine monophosphate \\
\hline ANOVA & Analysis of variance \\
\hline APS & Adhesion percentage scale \\
\hline APTT & Activated partial thromboplastin time \\
\hline ASD & Atrial septal defect \\
\hline ATP & Adenosine triphosphate \\
\hline ATTS & Adhesive tissue tenacity scale \\
\hline CAG & Coronary artery grafting \\
\hline Camp & 3', 5'-adenosine monophosphate \\
\hline $\mathrm{COX}$ & Cyclooxygenase \\
\hline COX-1 & Cyclooxygenase-1 \\
\hline $\mathrm{COX}-2$ & Cyclooxygenase- 2 \\
\hline CRP & C-reactive protein \\
\hline DAG & Diacylglycerol \\
\hline ECG & Electrocardiogram \\
\hline EDTA & Ethylene diamine tetra acetic acid \\
\hline ELAM-1 & Endothelial-leukocyte adhesion molecule-1 \\
\hline ESR & Erythrocyte sedimentation rate \\
\hline HETEs & Hydroxyeicosatetranoic acids \\
\hline HPETEs & Hydroperoxyeicosatetranoic acid compounds \\
\hline HPLC & High pressure liquid chromatography \\
\hline $\mathrm{IC}$ & Inhibitory concentration \\
\hline ICAM-1 & Intercellular adhesion molecule-1 \\
\hline IL-1 & Interleukin 1 \\
\hline IL-8 & Interleukin 8 \\
\hline INR & International normalization ratio \\
\hline IP3 & Inositol-1,4,5-triphosphate \\
\hline LFA & Lymphocyte function-associated antigen \\
\hline
\end{tabular}




\begin{tabular}{|c|c|}
\hline LTA4 & Leukotriene A4 \\
\hline LTD4 & Leukotriene D4 \\
\hline LTE4 & Leukotriene E4 \\
\hline MANOVA & Multivariate analysis of variance \\
\hline MRNA & Messenger ribonucleic acid \\
\hline N/D & Not detectable \\
\hline NSAIDs & Non-steroidal anti-inflammatory drugs \\
\hline NSW & New South Wales \\
\hline $\mathrm{NZ}$ & New Zealand \\
\hline PEG & Polyethyleneglycol \\
\hline PGD2 & Prostaglandin D2 \\
\hline PGE1 & Prostaglandin E1 \\
\hline PGE2 & Prostaglandin E2 \\
\hline PGF1 & Prostaglandin F1 \\
\hline PGF2 & Prostaglandin F2 \\
\hline PGI2 & Prostaglandin I2 \\
\hline PIP2 & Phosphatidylinositol-4, 5-biphosphate \\
\hline $\mathrm{PMN}$ & Polymorphonuclear \\
\hline PT & Prothrombin time \\
\hline QLD & Queensland \\
\hline SEM & Standard error of mean \\
\hline SRS-As & Slow-reacting substances of anaphylaxis \\
\hline TNF & Tumor necrosis factor \\
\hline TPA & Tissue plasminogen activator \\
\hline TxA2 & Thromboxane A2 \\
\hline $\mathrm{TxB} 2$ & Thromboxane B2 \\
\hline VIC & Victoria \\
\hline VSD & Ventricular septal defect \\
\hline WA & Western Australia \\
\hline WBC & White blood cells \\
\hline WCC & White Cell Count \\
\hline 5-LO & 5-lipoxygenase \\
\hline
\end{tabular}

